\title{
Detection of rabbit lgG by using functional magnetic particles and an enzyme-conjugated antibody with a homemade magnetic microplate
}

\author{
Hweiyan Tsai ${ }^{1,4^{*}}$, Yi-Hsuan Lu', Huan-Xuan Liao', Shih-Wei Wu' ${ }^{2}$, Feng-Yih Yu ${ }^{2}$ and Chwan Bor Fuh ${ }^{3}$
}

\begin{abstract}
Background: The enzyme-linked immunosorbent assay (ELISA) has been used for diagnosing medical and plant pathologies. In addition, it is used for quality-control evaluations in various industries. The ELISA is the simplest method for obtaining excellent results; however, it is time consuming because the immunoreagents interact only on the contact surfaces. Antibody-labeled magnetic particles can be dispersed in a solution to yield a pseudohomogeneous reaction with antigens which improved the efficiency of immunoreaction, and can be easily separated from the unreactive substances by applying a magnetic force. We used a homemade magnetic microplate, functional magnetic particles (MPs) and enzyme-labeled secondary antibody to perform the sandwich ELISA successfully.

Results: Using antibody-labeled MPs enabled reducing the analysis time to one-third of that required in using a conventional ELISA. The secondary antibody conjugated with horseradish peroxidase (HRP) was affinity-bound to the analyte (IgG in this study). The calibration curve was established according to the measured absorbance of the 3 , $3^{\prime}, 5,5^{\prime}$-tetramethybezidine-HRP reaction products versus the concentrations of standard lgG. The linear range of $\mathrm{lgG}$ detection was $114 \mathrm{ng} / \mathrm{mL}-3.5 \mathrm{ng} / \mathrm{mL}$. The limit of detection (LOD) of $\mathrm{lgG}$ was $3.4 \mathrm{ng} / \mathrm{mL}$. The recovery and coefficient of variation were $100 \%( \pm 7 \%)$ and $116 \%( \pm 4 \%)$ for the spiked concentrations of $56.8 \mathrm{ng} / \mathrm{mL}$ and $14.2 \mathrm{ng} / \mathrm{mL}$, respectively.

Conclusion: Pseudohomogeneous reactions can be performed using functional MPs and a magnetic microplate. Using antibody-labeled MPs, the analysis time can be reduced to one-third of that required in using a conventional ELISA. The substrate-enzyme reaction products can be easily transferred to another microplate, and their absorbance can be measured without interference by light scattering caused by magnetic microbeads. This method demonstrates great potential for detecting other biomarkers and in biochemical applications.
\end{abstract}

Keywords: Immunoassay, Functional magnetic particles, Magnetic separator

\section{Background}

In recent years, functionalized magnetic particles have attracted considerable research interest for many biological applications such as biomedicine [1-3], isolation of specific DNA [4], and manipulation of cells [5,6]. In addition, MPs have been used for detecting biomarkers by using superconducting quantum interference device (SQUID) [7-9]

\footnotetext{
* Correspondence: annetsai@csmu.edu.tw

'School of Medical Applied Chemistry, Chung Shan Medical University, Taichung 402, Taiwan

${ }^{4}$ Department of Medical Education, Chung Shan Medical University Hospital, Taichung 402, Taiwan

Full list of author information is available at the end of the article
}

and magnetic resonance [10]. We used MPs for detecting biomarkers by using various techniques [11-17], such as (1) predeposited the functionalized MPs in the thin channels coupling with a magnet, then captured the biomarker antibodies and analyzed by counting particles or off-line measurement of fluorescent intensity. (2) detected biomarker antibodies using functional nanomagnetic and fluorescent nanoparticles in magnetic microplate.

A sandwich enzyme-linked immunosorbent assay (ELISA) is a frequently employed bioanalytical assay that involves using an antibody-labeled solid phase to detect the presence of a substance, generally an antigen, in a liquid sample. An enzyme-conjugated secondary antibody is then 
added to form a sandwich structure. Thus, the enzymecatalyzed substrate reaction increases the sensitivity of the immunoassay. The ELISA has been used for diagnosing medical and plant pathologies. In addition, it has been used for quality-control evaluations in various industries. The ELISA is the simplest method for obtaining excellent results; however, it is time consuming because the immunoreagents interact only on the contact surfaces. We have improved the efficiency of the antigen-antibody reaction by integrating the sandwich immunoassay using functional magnetic and fluorescent nanoparticles in magnetic microplate. The magnetic microparticles were not suitable for direct measurement by microplate reader due the light scatting of the microparticles. In this study, we attempted to overcome this limitation using functional magnetic microparticles and an enzyme-conjugated antibody in a magnetic microplate. This method has many potential advantages which were reported in previous studies [17], such as (1) the amount of proteins immobilized on the particles is consistent in the same batch, which can be used for performing several reactions. (2) The magnetic microparticles (MPs) with avidin, carboxyl, or amino functional groups are commercial available which made antibody labeling easily. (3) MPs can be dispersed in a solution to yield a pseudohomogeneous reaction with antigens and can be easily separated from the unreactive substances by applying a magnetic force. (4) They can be redispersed in the solution after removing the magnetic force. (5) The enzyme-conjugated antibody can react with substrates pseudohomogeneously, and the products can be easily transferred from one microplate to another. The absorbance of the products can be measured without interference by light scattering caused by magnetic microbeads. The homogenous immunoreactions are more efficient than that of reaction on the surface of microplates [18]. Thus, in using antibody-labeled MPs, the time required for analysis is expected to be less than that required by a conventional ELISA. Most literatures on magnetic particle-based ELISA were processed in tubes $[19,20]$. The washing steps were done with one tube by one tube or with commercial magnetic separators, such as fully automated multisampling separators. The automated multisampling separators are expensive. Thus, we fabricated a practical and inexpensive magnetic microplate. The important contribution of our current work is the integration of microplate ELISA with homemade magnetic microplate. The process of the microplate ELISA will be more easily adopted in the clinical laboratory than tube-ELISA and the home made magnetic microplate is inexpensive.

Rabbits are among the most commonly used experimental animals in the areas of biochemical research and medical products. The serum immunoglobulin levels of an animal reflect its immune status. One of our coworkers used rabbits for performing immune experiments. Therefore, we used rabbit IgG as a model analyte to demonstrate our detection method. In this study, MPs were labeled with antiIgG, then IgG from the sample was bound to anti-IgG-MPs. A secondary antibody conjugated with horseradish peroxidase (HRP) was then used to bind to IgG. In the final step, enzyme substrates were added. The subsequent reaction produced a color change, and the absorbance of the product was measured.

\section{Materials and methods}

\section{Chemicals and materials}

An affinity isolated antibody, a buffered aqueous solution of biotinlyated antirabbit IgG antibody (whole-molecule), was produced in goat; rabbit IgG purified from a normal rabbit serum by using fractionation and ion-exchange chromatography; phosphate-buffered saline (PBS); dimethyl sulfoxide (DMSO); and 3,3',5,5'-tetramethybezidine (TMB) were purchased from Sigma-Aldrich (Saint Louis, MO, USA). Dynabeads ${ }^{\circ}$ MyOne $^{\text {Tx }}$ Streptavidin T1 (streptavidincoupled superparamagnetic beads $1 \mu \mathrm{m}$ in diameter) and Novex ${ }^{\circ}$ HRP-conjugated goat antirabbit IgG (H \& L) antibody were purchased from Life Technologies (Grand Island, NY, USA). Triton X-100 was purchased from Tedia (Fairfield, OH, USA). Hydrogen peroxide $\left(\mathrm{H}_{2} \mathrm{O}_{2}\right.$, $35 \%)$ was purchased from Shimakyu's Pure Chemicals (Osaka, Japan).

\section{Magnetic separator-magnetic microplate}

Permanent magnets $6 \mathrm{~mm}$ in diameter and $13 \mathrm{~mm}$ in length were fixed in the wells of a microplate, and the assembled magnetic microplate (Additional file 1: Figure S1) was then placed under another microplate to form a magnetic separator. The magnetic field strength of these magnets was $4.1( \pm 0.2) \mathrm{kG}$ at the top of separator.

\section{Instrumentation}

A spectrometer (Flexstation 3 multimode plate reader, Molecular Devices, Sunnyvale, CA, USA) was used to measure the optical intensity.

\section{Functional magnetic particle preparation (anti-lgG-labeled MPs)}

Streptavidin-coupled dynabeads were conjugated with biotinylated anti-IgG, based on the extremely high binding affinity of the streptavidin-biotin interaction $\left(K_{d}=10^{-15}\right)$, and further used for developing the pseudohomogeneous immunoassay. An aliquot of $100 \mu \mathrm{L}$ of biotinylated antiIgG $(3.3 \mathrm{mg} / \mathrm{mL})$ was added to a centrifuge tube containing $10 \mathrm{~mL}$ of PBS and $10 \mathrm{mg}$ dynabeads, and the tube was then gently rotated using a MACSmix ${ }^{\text {TM }}$ tube rotator for $2 \mathrm{~h}$ at $4^{\circ} \mathrm{C}$. Anti-IgG-labeled MPs were attracted by the magnets, and the MPs were washed three times with PBS to remove unreacted anti-IgG. Finally, anti-IgG-labeled MPs were reconstituted with $10 \mathrm{~mL}$ of PBS and divided 
into aliquots of $1 \mathrm{~mL}$ each. The aliquots were maintained at $4^{\circ} \mathrm{C}$ until use. The suspensions of the unreacted and washed PBS were mixed, and the protein concentration was evaluated using a Bradford reagent. The amount of labeled anti-IgG was approximately $18 \mu \mathrm{g} / \mathrm{mg}$ of dynabeads, which was semiquantitative based on the added amount subtracted from the amount left in the suspension. This result was consistent with that claimed by the supplier (biotinylated IgG up to $20 \mu \mathrm{g} / \mathrm{mg}$ of dynabeads).

\section{Procedures for the magnetic sandwich immunoassay}

Figure 1 shows the schematic of the reaction steps involved in IgG detection. This is a sandwich-type detection conducted by applying magnetic force and colorimetric detection. The procedures are briefly described as follows: In Step 1, an aliquot of $220 \mu \mathrm{L}$ of IgG standards or serum samples, and $10 \mu \mathrm{L}$ of $1 \mathrm{mg} / \mathrm{mL}$ anti-IgG-labeled MPs were added to the wells of the microplate. The mixture was then pipetted several times for mixing and incubated for $20 \mathrm{~min}$ at room temperature. In Step 2, the microplate was placed on top of a homemade magnetic microplate that attracted MPs to the bottom of the plate, and the remaining solution was gently removed. The microplates were then washed twice with PBS containing $0.1 \%$ BSA. In Step 3, $20 \mu \mathrm{L}$ of anti-IgG-HRP (dilution ratio of 1:1000) and $200 \mu \mathrm{L}$ of PBS were added to the microplates. The mixture was then pipetted several times for mixing and incubated for $30 \mathrm{~min}$ at room temperature. In Step 4, the unreacted anti-IgG-HRP was removed by washing the microplates twice with PBS containing $0.1 \%$ triton. The sandwich particles were resuspended in $200 \mu \mathrm{L}$ of buffer solutions containing the enzyme substrate (TMB/ $\mathrm{H}_{2} \mathrm{O}_{2}$ ). The enzyme substrates were $0.5 \mathrm{~mL}$ of TMB $\left(2.0 \mathrm{mg} / \mathrm{mL}\right.$ in DMSO) and $32 \mu \mathrm{L}$ of $0.75 \% \mathrm{H}_{2} \mathrm{O}_{2}$ freshly mixed with $10 \mathrm{~mL}$ of PBS. This is the reported optimized concentration of a TMB substrate [21]. In Step 5, finally, the microplate was placed on top of the homemade magnetic microplate, and $150 \mu \mathrm{L}$ of the solution was transferred to another microplate. An aliquot of $50 \mu \mathrm{L}$ of $1 \mathrm{M} \mathrm{HCl}$ was added to each well, and the absorbance for each sample was measured at $450 \mathrm{~nm}$. All experiments were performed in triplicate. Notably, the solution of dynabeads mixed with $1 \mathrm{M} \mathrm{HCl}$ gradually turned yellow, and the beads caused light scattering. Therefore, we transferred the products of the enzymesubstrate reaction to another microplate for subsequent measurements.

A calibration curve of the absorbance was established by plotting the measured absorbance versus the various known concentrations of IgG.

\section{Preparation of serum and spiked samples}

We drew blood from rabbits' ears. The rabbit antisera was precipitated using $\left(\mathrm{NH}_{4}\right)_{2} \mathrm{SO}_{4}$ to a final concentration of $50 \%$ and $35 \%$ in sequence by $100 \%$ saturated $\left(\mathrm{NH}_{4}\right)_{2} \mathrm{SO}_{4}$ solution. The precipitate was redissolved in distilled water equal to half of the original volume and then dialyzed against $2 \mathrm{~L}$ PBS for $72 \mathrm{~h}$ at $4^{\circ} \mathrm{C}$ with two changes of buffer. Finally, 0.01 M PBS was added to the original volume. The rabbits were New Zealand white rabbits (body weight, $3.5 \mathrm{~kg}$ ), which were obtained from Deer-Ho farm (Taichung, Taiwan) for immune experiments conducted by our coworkers. The animal experiments in our study were approved by the Institutional Animal Care and Use Committee at the Chung Shan Medical University (approval no. 1269). Prior to using the ELISA, the serum was diluted 10,000 times using PBS. To demonstrate the practicality of the proposed magnetic ELISA, IgG concentration in spiked serum samples was measured.
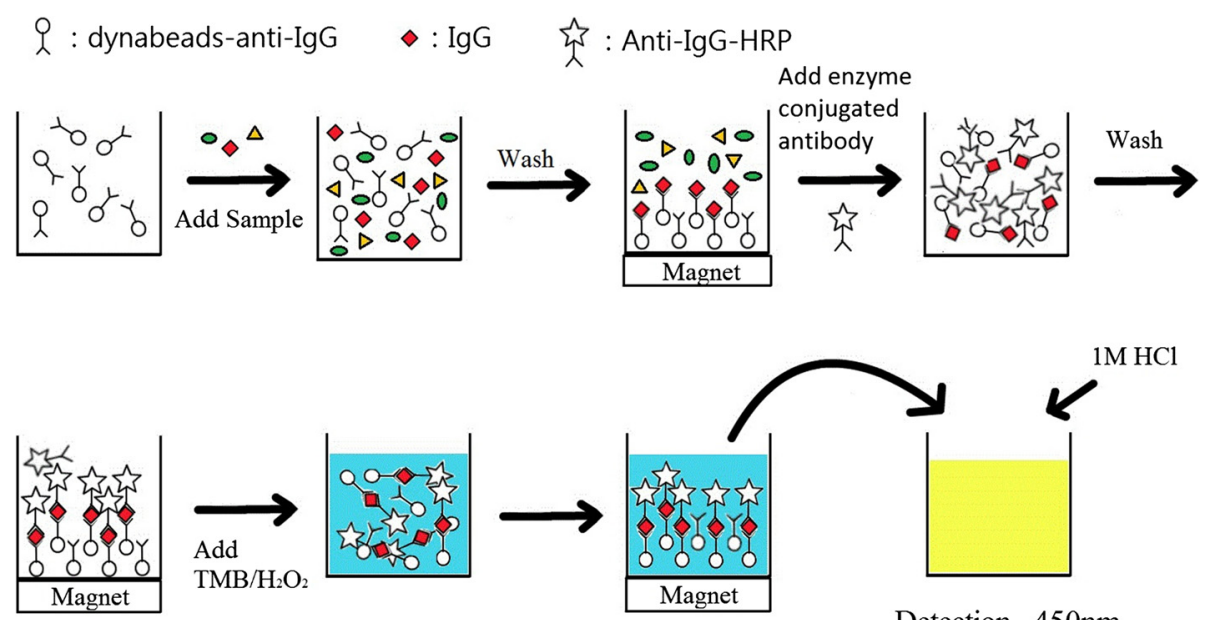

Detection 450nm

Figure 1 Schematic of immunoassay procedures for a magnetic ELISA. 
a)

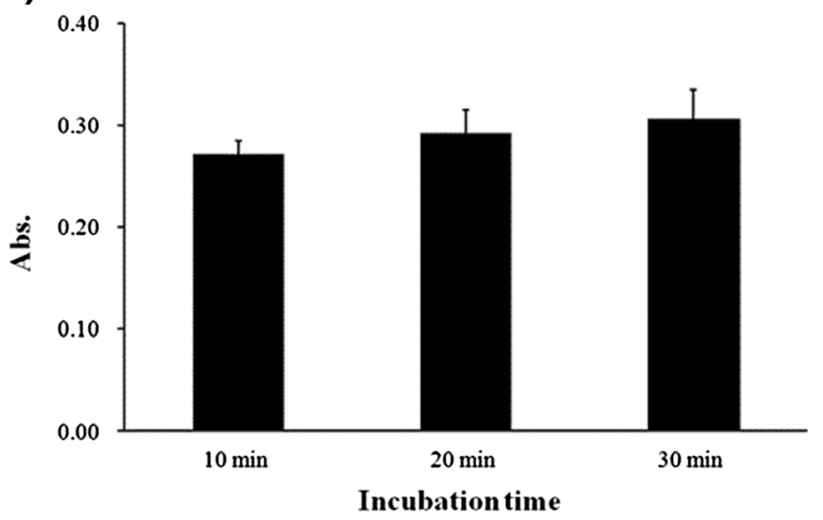

b)

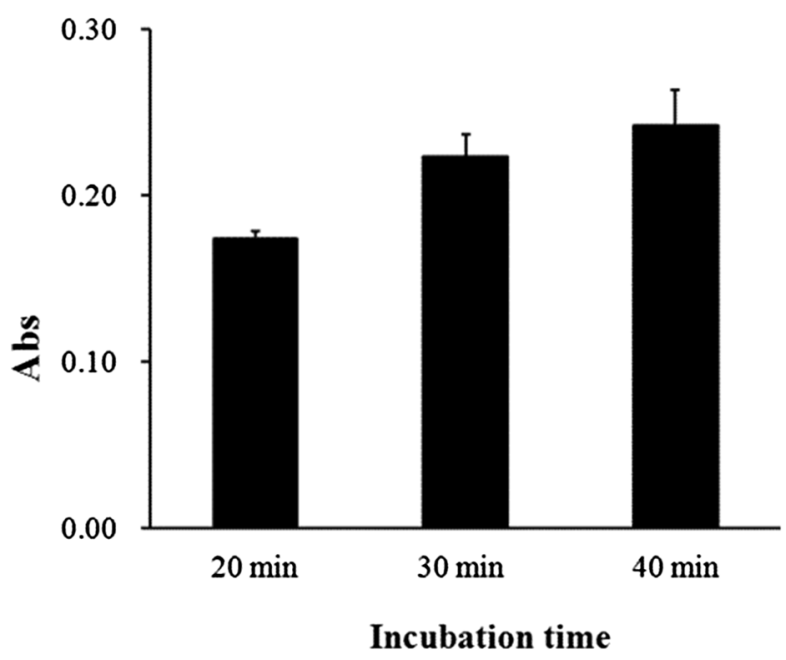

c)

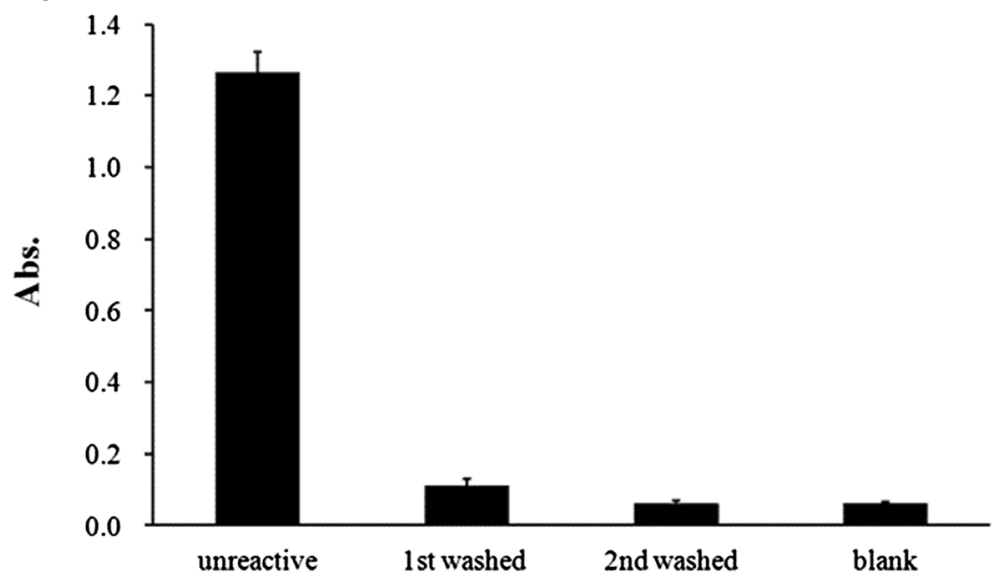

Figure 2 Optimization of immunoreaction time. (a) Effect of reaction time of anti-lgG-labeled MPs and IgG. (b) Effect of reaction time of anti-lgG-HRP with the microparticles to form the sandwich. (c) Relationship between washing times and the cleanliness of unreacted anti-lgG-HRP in the solution. "Unreactive" represents aliquots from the suspension of the mixture of anti-lgG-HRP and MP-anti-lgG-IgG after incubation. "1st washed" represents aliquots from the solution of the first washing. "2nd washed" represents aliquots from the solution after the second washing. "Blank" represents aliquots that contained only $\mathrm{TMB} / \mathrm{H}_{2} \mathrm{O}_{2}$ in PBS. 


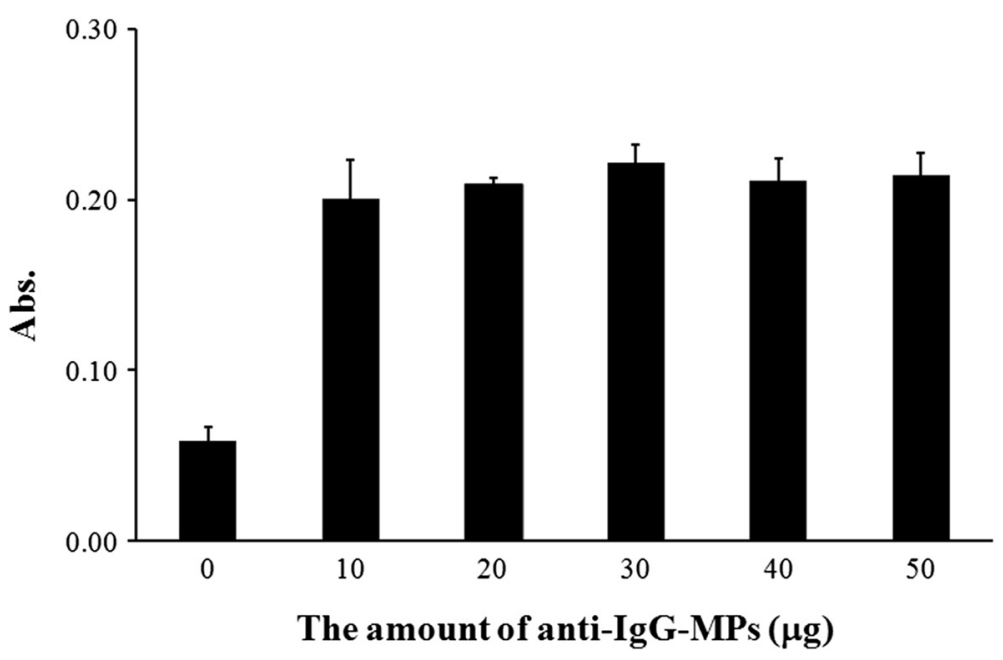

Figure 3 Effect of the amount of magnetic beads on the sensitivity. Here, $22.7 \mathrm{ng} / \mathrm{mL}$ (ie. $0.005 \mu \mathrm{g} / \mathrm{well}$ ) of IgG with varied amounts of anti-lgG-labeled MPs were incubated for 20 min and washed twice with PBS containing 0.1\% BSA. IgG was then reacted with anti-lgG-HRP for 30 min and washed twice with PBS containing $0.1 \%$ triton. Furthermore, $200 \mu \mathrm{L}$ of PBS containing TMB/H2O2 was added, and 150- $\mu \mathrm{L}$ aliquots were transferred to another microplate after $30 \mathrm{~min}$. Finally, $50 \mu \mathrm{L}$ of $1 \mathrm{M} \mathrm{HCl}$ was added to this microplate, and its absorbance was measured at $450 \mathrm{~nm}$.

\section{Results and discussion}

\section{Optimization of immunoreaction time}

The incubation time of an antibody and antigen is one of the crucial parameters for achieving a satisfactory sensitivity of an immunoassay [17]. Therefore, we varied the immunoreaction time from 10 to $30 \mathrm{~min}$. Figure 2a shows the performance results as a function of the incubation time of anti-IgG-labeled MPs and IgG. The duration of the sandwich immunoreaction (IgG and anti-IgG-HRP) was $30 \mathrm{~min}$. The amount of the HRP-TMB reaction products increased as the reaction time increased. We preliminarily applied $30 \mathrm{~min}$ for the enzyme-substrate reaction based on the balance of time consumption and detection sensitivity. The results showed that the intensity increased with longer incubation time; however, no significant difference was observed between the results of reactions performed for $20 \mathrm{~min}$ and $30 \mathrm{~min}$ (t-test, $\mathrm{p}=0.90$ ). Therefore, we applied an incubation time of $20 \mathrm{~min}$ for the first antibody-antigen reaction, and then further studied the secondary antibody reaction time of the sandwich immunoreaction (IgG and anti-IgG-HRP). Figure $2 \mathrm{~b}$ shows the performance results as a function of the incubation time of anti-IgG-HRP and MP-anti-IgG-IgG. No significant differences were observed between the results of reactions performed for $30 \mathrm{~min}$ and $40 \mathrm{~min}$ (t-test, $\mathrm{p}=0.33$ ). Therefore, we set $20 \mathrm{~min}$ for the primary immunoreaction and $30 \mathrm{~min}$ for the secondary immunoreaction as the optimized immunoreaction time.

Figure 2c shows the effect of wash times on the cleanliness of the unreactive anti-IgG-HRP. We transferred the suspension of the secondary immunoreaction and washed buffers to another microplate, and then removed $20 \mu \mathrm{L}$ of each solution to react with $200 \mu \mathrm{L}$ of PBS containing TMB/ $\mathrm{H}_{2} \mathrm{O}_{2}$. The results from the twice-washed buffer were not different from those of the blank that contained only the $\mathrm{TMB} / \mathrm{H}_{2} \mathrm{O}_{2}$ in buffer. Therefore, we washed the microplate only twice after each immunoreaction step.

\section{Effect of amount of magnetic beads}

The amount of dynabeads was relative to the amount of available anti-IgG; more antibodies reacted with more antigens, thereby leading to enhanced sensitivity and a wider dynamic range. By contrast, a large amount of the dynabeads caused particle aggregation. Therefore, we studied the effect of the amount of magnetic beads on sensitivity and linearity. The analysis of variance (ANOVA) statistical

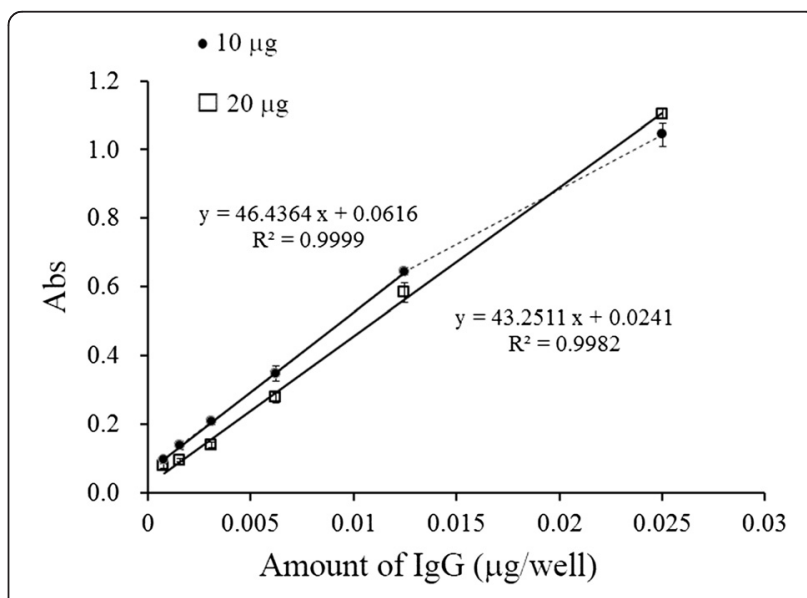

Figure 4 Plots of the calibration curves of IgG. The conditions of immunoreactions were the same as those shown in Figure 3. 
Table 1 Data of analytical specifications

\begin{tabular}{llllll}
\hline Amount of anti-lgG-MPs & Slope (Abs/ $\mathbf{\mu g})$ & $\mathbf{R}^{\mathbf{2}}$ & Range $(\mathbf{n g} / \mathbf{m L})$ & LOD $(\mathbf{n g} / \mathbf{m L})$ & Precision (reproducibility) \\
\hline $10 \mu \mathrm{g}$ & $46.3( \pm 0.3)$ & 0.9999 & $56.8 \sim 3.54$ & 0.59 & $2 \sim 10 \%$ \\
$20 \mu \mathrm{g}$ & $43.3( \pm 0.9)$ & 0.9982 & $113.6 \sim 3.54$ & 3.4 & $1 \sim 9 \%$ \\
\hline
\end{tabular}

results $(\mathrm{p}=0.487)$ showed no significant difference in the colorimetric intensities from the immunoreaction containing varied amounts of magnetic beads, as shown in Figure 3. This could have been due to the amount of labeled antiIgG being considerably greater than the amount of IgG in the solution.

Regarding the cost of the dynabeads and particle aggregation, we performed dose-dependent measurements of IgG with $10 \mu \mathrm{g}$ and $20 \mu \mathrm{g}$ of anti-IgG-labeled MPs.

\section{Calibration curve and reproducibility}

Calibration curves were established using commercial rabbit IgG, which was purified from the normal rabbit serum by using fractionation and ion-exchange chromatography. The plots of colorimetric absorbance of varied concentrations of IgG for the optimal reaction time are displayed in Figure 4. The linearity, slope, LOD, and precision are as shown in Table 1. As expected, the upper concentration of the linear range from $20 \mu \mathrm{g}$ of anti-IgGlabeled MPs was twice that from $10 \mu \mathrm{g}$ of anti-IgG-labeled MPs. The LOD based on $3 \mathrm{~S}_{\mathrm{b}} / \mathrm{m}$ was $0.59 \mathrm{ng} / \mathrm{mL}$ and $3.4 \mathrm{ng} / \mathrm{mL}$ for $10 \mu \mathrm{g}$ of anti-IgG-labeled MPs and $20 \mu \mathrm{g}$ of anti-IgG-labeled MPs, respectively. However, no significant difference was observed between their sensitivities.

The importance of precision has often been emphasized for using a bead-based immunoassay in quantitative analysis. The intraassay precision of the analytical method was calculated by analyzing each concentration in triplicate per run. The relative standard deviation was $1 \%-5 \%$ at varied concentration levels, except for $9 \%-10 \%$ at $3.5 \mathrm{ng} / \mathrm{mL}$. These results implied that the proposed method exhibited satisfactory reproducibility. The bioactivity of highly diluted HRP decayed rapidly. Aliquots of anti-IgG-HRP diluted 100 times were maintained at $4^{\circ} \mathrm{C}$. The working solution of anti-IgG-HRP was adjusted to 500-1000 dilutions based on a positive control test of the anti-IgG$\mathrm{HRP}-\mathrm{TMB} / \mathrm{H}_{2} \mathrm{O}_{2}$ reaction, which maintained an absorbance at 1.5. Thus, reproducibilities of the interassay were less than $7 \%$.

\section{Determination of IgG in rabbit serum sample}

An aliquot of $220 \mu \mathrm{L}$ of dilute rabbit serum was incubated with $20 \mu \mathrm{g}$ of anti-IgG-labeled MPs. The recovery was measured for the spiked IgG in serum at final concentrations of $56.8 \mathrm{ng} / \mathrm{mL}$ and $14.2 \mathrm{ng} / \mathrm{mL}$. The IgG concentration in the obtained serum and spiked solutions was measured and interpreted according to the calibration curve. The IgG concentration of the rabbit serum was
$7.66 \mathrm{mg} / \mathrm{mL}( \pm 3 \%)$, which is consistent with that reported (5-10 $\mathrm{mg} / \mathrm{mL}$ ) by a previous study [22]. The recovery and coefficient of variation were $100 \%( \pm 7 \%)$ and $116 \%( \pm 4 \%)$ for the spiked concentrations of $56.8 \mathrm{ng} / \mathrm{mL}$ and $14.2 \mathrm{ng} /$ $\mathrm{mL}$, respectively.

\section{Conclusion}

We developed an ELISA that combines the sandwich immunoassay with MPs and an enzyme-conjugated secondary antibody on a magnetic microplate for determining the IgG concentration in a buffer solution and serum. The high sensitivity of the assay was achieved using the colorimetric method for measuring the activity of the conjugated HRP. The dynamic working range was 114-3.5 ng/ $\mathrm{mL}$. The recovery ranged from $100 \%$ to $116 \%$, and reproducibility ranged from $1 \%$ to $10 \%$. In using antibody-labeled MPs, the time required for analysis was reduced to onethird of that required in using a conventional ELISA. The detection limit was $3.4 \mathrm{ng} / \mathrm{mL}$ (i.e. $2.3 \times 10^{-11} \mathrm{M}$ ) which was lower than $10^{-9}-10^{-10} \mathrm{M}$ suggested by the vendors of conventional ELISA kits and time-resolved fluorescence [23]. The homemade magnetic microplate was practical and inexpensive. This method has satisfactory potential for detecting other biomarkers and in biochemical applications.

\section{Additional file}

Additional file 1: Figure S1. The homemade magnetic microplate.

Competing interests

The authors declare that they have no competing interests.

\section{Authors' contributions}

HT substantially contributed to the conception, analysis and interpretation of the data, and drafting of the manuscript. $\mathrm{YL}$ and $\mathrm{HL}$ performed the magnetic immunoassay and data collection. SW and FY conducted the rabbit serum preparation. CF participated in the design and results discussion. All of the authors have read and approved the final manuscript.

\section{Acknowledgments}

The authors gratefully acknowledge the financial support from the Ministry of Science and Technology, Taiwan (NSC 102-2113-M-040-002).

\section{Author details}

${ }^{1}$ School of Medical Applied Chemistry, Chung Shan Medical University, Taichung 402, Taiwan. ${ }^{2}$ School of Biomedical Sciences, Chung Shan Medical University, Taichung 402, Taiwan. ${ }^{3}$ Department of Applied Chemistry, National Chi Nan University, Puli, Nantou 545, Taiwan. ${ }^{4}$ Department of Medical Education, Chung Shan Medical University Hospital, Taichung 402, Taiwan.

Received: 16 October 2014 Accepted: 6 February 2015

Published online: 22 February 2015 


\section{References}

1. Morimoto $Y$, Natsume $H$. Targeting technology utilizing magnetic microparticulate system for cancer therapy. Jpn J Clin Med. 1998;56:649-56.

2. Saini G, Shenoy D, Nagesha DK, Kautz R, Sridhar S, Amiji M. Superparamagnetic iron oxide-gold core-shell nanoparticles for biomedical applications. 2005 NSTI Nanotechnology Conference and Trade Show - NSTI Nanotech 2005 Technical Proceedings. 2005;328-331.

3. Blackburn WH, Dickerson EB, Smith MH, McDonald JF, Lyon LA Peptide-functionalized nanogels for targeted siRNA delivery. Bioconjug Chem. 2009;20:960-8.

4. Kinsella JM, Ivanisevic A. Enzymatic clipping of DNA wires coated with magnetic nanoparticles. J Am Chem Soc. 2005;127:3276-7.

5. Pisanic li TR, Blackwell JD, Shubayev VI, Fiñones RR, Jin S. Nanotoxicity of iron oxide nanoparticle internalization in growing neurons. Biomaterials. 2007;28:2572-81

6. Van Den Bos EJ, Wagner A, Mahrholdt H, Thompson RB, Morimoto $Y$, Sutton BS, et al. Improved Efficacy of Stem Cell Labeling for Magnetic Resonance Imaging Studies by the Use of Cationic Liposomes. Cell Transplant. 2003;12:743-56.

7. Horng HEY SY, Huang YW, Jiang WQ, Hong C-Y, Yang HC. Nanomagnetic particles for SQUID-based magnetically labeled immunoassay. IEEE Trans Appl Supercond. 2005;15:668-71.

8. Tsukamoto A, Kuma H, Saitoh K, Kandori A, Yoshinaga K, Sugiura Y, et al. Reduction of the magnetic signal from unbound magnetic markers for magnetic immunoassay without bound/free separation. Physica C. 2007:463-465:1024-8.

9. Kuma H, Oyamada H, Tsukamoto A, Mizoguchi T, Kandori A, Sugiura Y, et al. Liquid phase immunoassays utilizing magnetic markers and SQUID magnetometer. Clin Chem Lab Med. 2010;48:1263-9.

10. Wagner S, Schnorr J, Pilgrimm H, Hamm B, Taupitz M. Monomer-coated very small superparamagnetic iron oxide particles as contrast medium for magnetic resonance imaging: Preclinical in vivo characterization. Invest Radiol. 2002;37:167-77.

11. Fuh CB, Su YS, Tsai HY. Determination of magnetic susceptibility of various ion-labeled red blood cells by means of analytical magnetapheresis. J Chromatogr A. 2004;1027:289-96.

12. Tsai HY, Yin C, Lin YP, Fuh CB. New method of blood typing using analytical magnetapheresis. J Chromatogr A. 2006;1120:35-7.

13. Tsai HY, Hsu CF, Chiu IW, Fuh CB. Detection of C-reactive protein based on immunoassay using antibody-conjugated magnetic nanoparticles. Anal Chem. 2007;79:8416-9.

14. Tsai H, Lin Y, Chang HW, Fuh CB. Integrating the QCM detection with magnetic separation for on-line analysis. Biosens Bioelectron. 2008;24:485-8.

15. Tsai HY, Jian SJ, Huang ST, Fuh CB. Competitive magnetic immunoassay for protein detection in thin channels. J Chromatogr A. 2009;1216:7493-6.

16. Tsai HY, Chan JR, Li YC, Cheng FC, Fuh CB. Determination of hepatitis B surface antigen using magnetic immunoassays in a thin channel. Biosens Bioelectron. 2010;25:2701-5.

17. Tsai HY, Chang CY, Li YC, Chu WC, Viswanathan K, Bor Fuh C. Detection of carcinoembryonic antigen using functional magnetic and fluorescent nanoparticles in magnetic separators. J Nanopart Res. 2011;13:2461-7.

18. Farrell S, Ronkainen-Matsuno NJ, Halsall HB, Heineman WR. Bead-based immunoassays with microelectrode detection. Anal Bioanal Chem. 2004;379:358-67.

19. Song F, Zhou Y, Li YS, Meng XM, Meng XY, Liu JQ, et al. A rapid immunomagnetic beads-based immunoassay for the detection of $\beta$-casein in bovine milk. Food Chem. 2014;158:445-8.

20. Lei JH, Guan F, Xu H, Chen L, Su BT, Zhou Y, et al. Application of an immunomagnetic bead ELISA based on IgY for detection of circulating antigen in urine of mice infected with Schistosoma japonicum. Vet Parasitol. 2012;187:196-202.

21. Li H, Chen J, Xu F, Cao H, Maria E. Optimization of TMB substrate chromogenic system in ELISA and the study of its stability in storage. Biotechnol Bull. 2010:2:126-30.

22. Farrell Jr HM, Jimenez-Flores R, Bleck GT, Brown EM, Butler JE, Creamer LK, et al. Nomenclature of the proteins of Cows' milk—sixth revision. J Dairy Sci. 2004;87:1641-74.

23. Ozinskas AJ. Topics in Fluorescence Spectroscopy: Volume 4: Probe Design and Chemical Sensing. In: Springer Science \& Business Media. 1994.

\section{Publish with ChemistryCentral and every scientist can read your work free of charge \\ "Open access provides opportunities to our colleagues in other parts of the globe, by allowing anyone to view the content free of charge." \\ W. Jeffery Hurst, The Hershey Company. \\ - available free of charge to the entire scientific community \\ - peer reviewed and published immediately upon acceptance \\ - cited in PubMed and archived on PubMed Central \\ - yours - you keep the copyright \\ Submit your manuscript here: \\ http://www.chemistrycentral.com/manuscript/<smiles>c1ccccc1</smiles> \\ Chemistry Central}

